\title{
ANÁLISE ERGONÔMICA DO TRABALHO EM UMA EMPRESA DE SERVIÇOS DO RAMO ALIMENTÍCIO
}

Daiane de Oliveira Costa (Universidade Federal do Ceará) daiane_oliveirac@ hotmail.com Sâmara Margarida Santana Soares (Universidade Potiguar) smargarida-@hotmail.com Rayane Araújo Lima (Universidade Federal do Ceará) rayanearaujo@alu.ufc.br Hévilla Souza Oliveira (Universidade Federal do Ceará) hevillasouza@alu.ufc.br Carla Amanda Matos Lima (Universidade Federal do Ceará) amandamtsl@alu.ufc.br

\section{Resumo}

Um dos principais ativos existentes dentro das empresas são os colaboradores, tendo em vista que o valor para os clientes é agregado à medida que os produtos e serviços são modificados por estes. Assim, a ergonomia é uma das áreas da engenharia que tem como objetivo modificar o sistema de trabalho para adequá-lo à realidade do trabalhador, de modo a tornar este ambiente o mais seguro e confortável possível. Tendo em vista a importância das condições psicofisiológicas dos funcionários, realizou-se uma Análise Ergonômica do Trabalho (AET) no posto de trabalho de operador de caixa em um restaurante localizado na cidade de Mossoró-RN, com o objetivo de sugerir melhorias para garantir o bem-estar do funcionário na realização de suas atividades, visando também a melhoria da produtividade. Para tal, aplicou-se o Métodolo RULA (Rapid Upper Limb Assessment) para formulação da problemática ergonômica, onde observou-se riscos à saúde da funcionária, e o Questionário Bipolar para a análise da fadiga durante a sua jornada de trabalho. Além desses métodos, foi elaborado e aplicado um questionário semi-estruturado com a finalidade de investigar demais aspectos associados às condições do trabalho. O estudo foi finalizado com a ferramenta 5W2H para as recomendações de implantação das melhorías, de modo a garantir a saúde e bem estar da colaboradora.

Palavras-Chaves: Análise Ergonômica do Trabalho. Método RULA. Operador de Caixa. 


\section{Introdução}

Por ser um dos inputs fundamentais para que as atividades nas organizações sejam realizadas de maneira eficiente, um dos principais ativos de uma empresa são os colaboradores. Tanto nos processos produtivos quanto nos serviços, estes devem possuir conforto e segurança durante as atividades desempenhadas, tendo em vista que o valor é agregado à medida que os produtos e serviços são modificados por esta mão de obra.

A ergonomia é uma das áreas da engenharia que tem como objetivo modificar o sistema de trabalho para adequá-lo à realidade do trabalhador. Segundo Iida (2016), a ergonomia inicia os seus estudos fazendo um levantamento das características dos trabalhadores para então elaborar projetos que atendam às suas necessidades ergonômicas. Dentre as diversas regulamentações existentes no Brasil, a Norma Regulamentadora 17 (NR-17), “estabelece parâmetros que permitem adaptações do ambiente de trabalho às condições psicofisiológicas dos trabalhadores" (NR-17, 2018). Em seu Anexo I, esta norma estabelece os parâmetros e diretrizes mínimas para adequação das condições de trabalho dos operadores de checkout, os quais se assemelham ao objeto de estudo desta pesquisa.

No que se refere à função de um operador de caixa, pode-se afirmar que este tipo de serviço abrange um modelo de situação crítica devido ao fato de lidar com atores distintos - cliente, chefia e atendente - e responder a diferentes necessidades, o que resulta em tensão excessiva e elevados níveis de estresse (FERREIRA, 2000; BALLONE, 2008 apud BRAGA et al., 2013). Tendo em vista a importância da valorização do colaborador no que diz respeito às suas condições psicofisiológicas, este estudo tem como objetivo a realização de uma Análise Ergonômica do Trabalho (AET) no posto de operador de caixa, em um restaurante localizado na cidade de Mossoró-RN, de modo a sugerir melhorias para garantir o bem-estar do funcionário na realização de suas atividades, visando, também, a melhoria da sua produtividade.

\section{Referencial teórico}

\subsection{Ergonomia}

De acordo com Iida (2016) a ergonomia consiste no estudo para a adaptação do projeto de trabalho às capacidades e limitações daquele que irá executá-lo, ou seja, o homem, envolvendo todas as circunstâncias que podem influenciar no convívio entre este e seu trabalho, tais como máquinas, equipamentos, ambiente físico e também aspectos organizacionais. Assim, a ergonomia deve transformar o trabalho de modo que possibilite aos 
trabalhadores exercerem as competências envolvidas em suas funções sem alterar a sua condição de saúde ao passo que permite à organização alcançar os objetivos financeiros estabelecidos (GUÉRIN et al., 2001).

\subsection{Análise ergonômica do trabalho}

De acordo com Doppler (2018), a aplicação da ergonomia com o intuito da diminuição dos riscos e prevenção de acidentes no ambiente de trabalho, possibilita grande colaboração e auxílio na saúde dos colaboradores. Abrahão et al. (2009) descrevem sobre a importância da análise das condições de trabalho, sendo essas a infraestrutura física e os materiais no ambiente profissional, devido a constância que são empregados nas atividades da organização e os impactos que podem gerar tanto nas operações diárias quanto na saúde dos funcionários.

Guérin et al. 2001 apud Iida (2005), afirmam que a AET busca melhorias do ambiente de trabalho por meio de estudos e diagnósticos para recomendações de correções, sendo essa metodologia geralmente dividida em cinco etapas (Quadro 1).

Quadro 1 - Fases do AET

\begin{tabular}{|l|}
\hline \multicolumn{1}{|c|}{ Análise da demanda } \\
\hline $\begin{array}{l}\text { Definição da problemática da ergonômica, no qual busca determinar a } \\
\text { natureza, a dimensão das situações enfrentadas, aspectos como uma } \\
\text { estimativa de gastos e prazos para a solução do caso. }\end{array}$ \\
\hline \multicolumn{1}{c|}{ Análise da tarefa } \\
\hline $\begin{array}{l}\text { Investigação se as operações recomendadas para a realização das tarefas } \\
\text { estão realmente colocadas em prática pelos colaboradores ou possiveis } \\
\text { de acordo com o cenário no ambiente de trabalho. }\end{array}$ \\
\hline \multicolumn{1}{c|}{ Análise da atividade } \\
\hline $\begin{array}{l}\text { Esta etapa está relacionada com conduta dos funcionários durante a } \\
\text { execução das atividades, dessa forma busca a análise do comportamento } \\
\text { decorrente de fatores internos e externos durante o trabalho. }\end{array}$ \\
\hline \multicolumn{1}{c|}{ Formulação do diagnóstico } \\
\hline $\begin{array}{l}\text { Objetiva a identificação das causas raizes dos problemas ergonomicos, } \\
\text { sejam esses decorrentes as atividades efetuadas ou da própria instituição. }\end{array}$ \\
\hline $\begin{array}{l}\text { Riz respeito às medidas para a resolução da problemática em questão, } \\
\text { devendo essas apresentar clareza, detalhamentos, responsabilidades bem } \\
\text { como o periodo indicado para cada ação. }\end{array}$ \\
\hline
\end{tabular}

Fonte: Adaptado de Iida (2005) 


\subsection{NR-17}

Esta NR, instituída pelo Ministério do Trabalho no ano de 1978, estabelece parâmetros relacionados ao mobiliário, levantamento, transporte e descarga de materiais, equipamentos, bem como às condições ambientais, incluindo a organização do local de trabalho (NR-17, 2018).

O Anexo I trata das operações de checkout, posto que se aproxima do avaliado nesse estudo. Neste anexo, a NR determina que deve ser assegurada uma postura de trabalho confortável aos membros superiores e inferiores do funcionário, espaço adequado para livre movimentação na cadeira, apoio para os pés, respeito dos limites naturais dos movimentos corporais durante a execução das atividades etc. (NR-17, 2018).

\subsection{Método RULA}

O método RULA (Rapid Upper Limb Assessment) trata-se de um método para o estudo ergonômico de distúrbios aos quais estão acometidos os membros superiores dos colaboradores em seus postos de trabalho. Equivale ressaltar que para a aplicação do método é dispensável o uso de equipamentos especiais a fim de mensurar possíveis riscos associados ao pescoço, tronco e membros superiores. Por meio deste é possível definir aspectos como número de movimentos, trabalho muscular estático, força e posturas (MCATAMNEY \& CORLETT, 1993).

\subsection{Questionário bipolar}

A principal função do Questionário Bipolar refere-se à avaliação da sensação de fadiga por parte do colaborador, embasados nos relatos dos próprios, durante três momentos em um dia de trabalho, sendo estes no início do expediente, antes de iniciar o intervalo para o almoço e no final do dia de trabalho. Os testes qualitativos que constituem o questionário em questão foram desenvolvidos por Nigel Corlett, sendo conhecido também por Escalas de Likert (MÁSCULO \& VIDAL, 2011; PEREIRA, 2013 apud SILVA \& CABETE, 2018).

\section{$2.65 \mathrm{~W} 2 \mathrm{H}$}

O 5W2H consiste em uma ferramenta amplamente utilizada para auxiliar no processo de tomada de decisão bem como acompanhamento e implementação de um determinado plano de ação. Utilizado em diversas áreas, este método consiste em responder perguntas que irão fornecer as informações necessárias para auxiliar o planejamento em questão. Sua terminologia tem origem na língua inglesa e contempla sete questionamentos: what (o que), 
who (quem), why (por quê), where (onde), when (quando), how (como) e how much (quanto) (DAYCHOUM, 2012; MACHADO, 2012).

\section{Metodologia}

\subsection{Caracterização da pesquisa}

Com o intuito de aprofundar os conhecimentos dos pesquisadores sobre os temas de interesse, iniciou-se o estudo com uma revisão bibliográfica. A pesquisa é de natureza aplicada, pois tem como finalidade a resolução de uma problemática existente, além de possibilitar uma aplicação dos conceitos e análises efetuados, permitindo o alcance de resultados. Em relação ao objetivo, caracteriza-se como descritiva e exploratória, pois busca descrever as características do objeto de estudo para uma maior compreensão do problema visando a proposição de ideias.

Já a abordagem é qualitativa, visto que se baseou em entrevistas e métodos de cunho subjetivo. O procedimento é descrito como um estudo de caso, visto o aprofundamento e compressão sobre o fenômeno investigado, buscando-se descobertas de aspectos e relações que poderiam continuar ocultas sem um estudo intensivo (FACHIN, 2017).

\subsection{Coleta de dados e informações sobre a função do trabalhador}

A etapa inicial consistiu em uma visita e coleta de dados realizada no dia 12/04/2020 em um restaurante, localizado na cidade de Mossoró-RN. Nessa oportunidade, definiu-se como objeto de estudo o posto de trabalho de operador de caixa, no qual um único funcionário realiza a função. Este é do sexo feminino, possui estatura de 1,65 metros e 25 anos. A jornada de trabalho é de 6 horas diárias de terça-feira à domingo.

Realizou-se também a análise do ambiente de trabalho, observando as atividades efetuadas e a interação da colaboradora com a infraestrutura da organização. Para a formulação da problemática ergonômica, foi aplicado o método RULA, no qual ocorreu a subdivisão das atividades do setor de operador de caixa e observou-se os riscos para cada uma dessas operações. Além do método citado, empregou-se o Questionário Bipolar com o intuito de analisar a fadiga da colaboradora durante sua jornada de trabalho. Foi realizada também uma entrevista semiestruturada com a finalidade de investigar demais aspectos associados à condição do trabalho, como sobrecarga, relações pessoais na organização, dentre outros. 
Com base nas definições dos níveis de ação indicados no RULA e os resultados dos demais questionários, foram propostas melhorias utilizando a ferramenta 5W2H para auxiliar suas implantações. Finalizou-se a pesquisa com as considerações finais e sugestões para trabalhos futuros.

\section{Descrição do posto de trabalho e das atividades}

A funcionária trabalha sentada em uma cadeira, de frente para uma mesa, onde teclado e mouse estão no plano horizontal, enquanto o monitor do computador está no plano vertical. Também há uma bancada, onde é feito o atendimento aos clientes, conforme a Figura 1.

Figura 1 - Posto de trabalho de operador de caixa

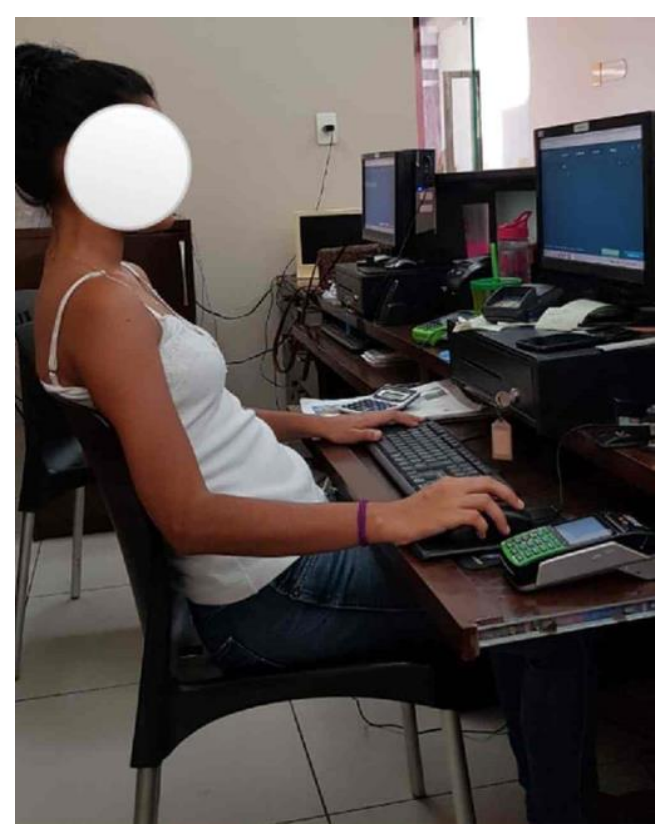

Fonte: Autores (2020)

As atividades realizadas consistem em: atender o cliente na chegada ao caixa, liberar o caixa para início da operação, conferência de consumo e atendimento ao cliente para finalização e recebimento do pagamento. Essas atividades se repetem ao longo da jornada de 6 horas, onde seus principais movimentos são com os braços, mãos e punhos.

Em relação ao mobiliário e equipamentos utilizados para execução das atividades, tem-se: um computador e seus acessórios; uma impressora fiscal; uma máquina de cartão; uma bancada de apoio ao computador; uma cadeira; materiais de escritório.

Com relação às condições ambientais de trabalho, na NR-17 (2018), o item 17-5 trata especificamente disto, fornecendo parâmetros para adaptação do ambiente a níveis adequados 
de ruído, limites de temperatura efetiva admissíveis de 20 a $23^{\circ} \mathrm{C}$, limite máximo de velocidade do ar de $0,75 \mathrm{~m} / \mathrm{s}$, e limite mínimo de umidade relativa de $50 \%$.

\section{Resultados e discussões}

\subsection{Aplicação do método RULA}

Com o objetivo de conhecer melhor as posturas em que a operadora de caixa realiza suas atividades, foi aplicado o método RULA.

Para a sua aplicação é necessário primeiro a divisão da tarefa em atividades:

I. Atender o cliente na chegada ao caixa;

II. Liberar o caixa para início da operação;

III. Conferência de consumo;

IV. Atendimento ao cliente para finalização e recebimento do pagamento.

Uma vez que as atividades foram divididas, pode-se iniciar a aplicação do método a cada uma destas, seguindo os passos adiante:

Atividade I: Atender o cliente na chegada ao caixa;

a) Qualificar a posição do braço:

O braço apresenta uma angulação entre $20^{\circ}$ e $45^{\circ}$, conforme a Figura 2.

Figura 2 - Posição do braço na atividade I

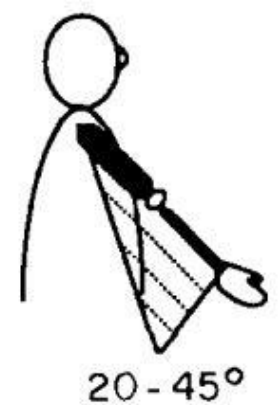

Fonte: McAtamney \& Corlett (1993)

Esse posicionamento configura uma pontuação +2 . Porém, como o ombro estar elevado, o valor é acrescido de +1 , logo, obtém-se um total de 3 pontos.

b) Qualificar a posição do antebraço:

O antebraço apresenta uma angulação de $100^{\circ}$ acima, conforme a Figura 3. 
Figura 3 - Posição do antebraço na atividade I

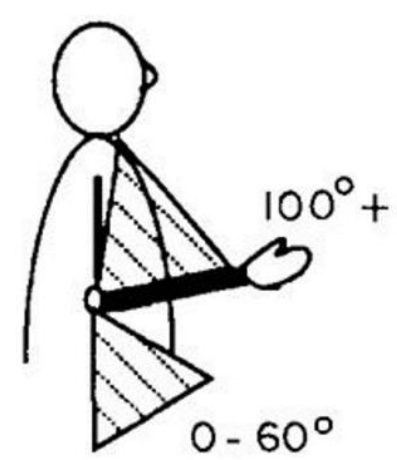

Fonte: McAtamney \& Corlett (1993)

Esse posicionamento configura uma pontuação +2 .

c) Qualificar a posição do punho:

O punho apresenta uma angulação de $0^{\circ}$, conforme a Figura 4.

Figura 4 - Posição do punho na atividade I

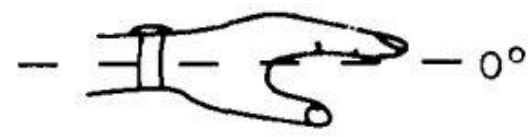

Fonte: McAtamney \& Corlett (1993)

Esse posicionamento configura uma pontuação +1 .

d) Qualificar a rotação do punho:

O punho não apresenta rotação, esse aspecto pode ser avaliado conforme a Figura 5.

Figura 5 - Rotação do punho na atividade I

\begin{tabular}{|c|c|}
\hline 1 & Faixa intermédiária de rotação \\
\hline 2 & No final ou próximo ao fim da faixa de rotação \\
\hline
\end{tabular}

Fonte: Adaptado de McAtamney \& Corlett (1993)

Esse posicionamento configura uma pontuação +1 .

Uma vez encontrados as pontuações referentes aos braços, antebraços e punhos, pode-se qualificar a postura de acordo com o Quadro 2. 
Quadro 2 - Pontuação dos braços, antebraços e punhos

\begin{tabular}{|c|c|c|c|c|c|c|c|c|c|}
\hline \multirow{4}{*}{ BRAÇO } & \multirow{4}{*}{ ANTEBRAÇO } & \multicolumn{8}{|c|}{ POSICÃO DO PUNHO } \\
\hline & & & & & & & & & \\
\hline & & \multicolumn{2}{|c|}{ Rotacão } & \multicolumn{2}{|c|}{ Rotacão } & \multicolumn{2}{|c|}{ Rotacão } & \multicolumn{2}{|c|}{ Rotacão } \\
\hline & & 1 & 2 & 1 & 2 & 1 & 2 & 1 & 2 \\
\hline \multirow{3}{*}{1} & 1 & 1 & 2 & 2 & 2 & 2 & 3 & 3 & 3 \\
\hline & 2 & 2 & 2 & 2 & 2 & 3 & 3 & 3 & 3 \\
\hline & 3 & 2 & 3 & 3 & 3 & 3 & 3 & 4 & 4 \\
\hline \multirow{3}{*}{2} & 1 & 2 & 3 & 3 & 3 & 3 & 4 & 4 & 4 \\
\hline & 2 & 3 & 3 & 3 & 3 & 3 & 4 & 4 & 4 \\
\hline & 3 & 3 & 4 & 4 & 4 & 4 & 4 & 5 & 5 \\
\hline \multirow{3}{*}{3} & 1 & 3 & 3 & 4 & 4 & 4 & 4 & 5 & 5 \\
\hline & 2 & 3 & 4 & 4 & 4 & 4 & 4 & 5 & 5 \\
\hline & 3 & 4 & 4 & 4 & 4 & 4 & 5 & 5 & 5 \\
\hline \multirow{3}{*}{4} & 1 & 4 & 4 & 4 & 4 & 4 & 5 & 5 & 5 \\
\hline & 2 & 4 & 4 & 4 & 4 & 4 & 5 & 5 & 5 \\
\hline & 3 & 4 & 4 & 4 & 5 & 5 & 5 & 6 & 6 \\
\hline \multirow{3}{*}{5} & 1 & 5 & 5 & 5 & 6 & 6 & 6 & 6 & 7 \\
\hline & 2 & 5 & 6 & 6 & 6 & 6 & 7 & 7 & 7 \\
\hline & 3 & 6 & 6 & 6 & 7 & 7 & 7 & 7 & 8 \\
\hline \multirow{3}{*}{6} & 1 & 7 & 7 & 7 & 7 & 7 & 8 & 8 & 9 \\
\hline & 2 & 8 & 8 & 8 & 8 & 8 & 9 & 9 & 9 \\
\hline & 3 & 9 & 9 & 9 & 9 & 9 & 9 & 9 & 9 \\
\hline
\end{tabular}

Fonte: Adaptado de McAtamney \& Corlett (1993)

A pontuação da postura encontrada para atividade I no Quadro 2 foi de 3 pontos.

e) O próximo passo é qualificar a posição do pescoço:

O pescoço apresenta uma posição em extensão, conforme a Figura 6.

Figura 6 - Posição do pescoço na atividade I

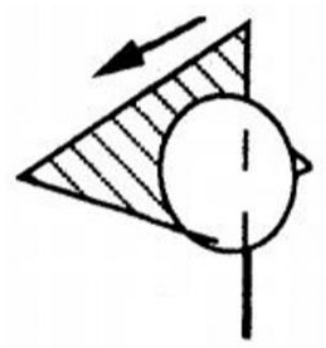

Fonte: McAtamney \& Corlett (1993)

Esse posicionamento configura uma pontuação +4 .

f) Qualificar a posição do tronco:

O tronco apresenta uma angulação entre $0^{\circ}$ e $20^{\circ}$, conforme a Figura 7. 
Figura 7 - Posição do tronco na atividade I

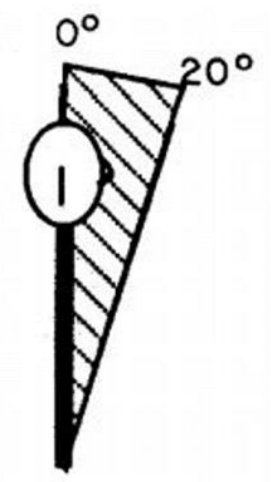

Fonte: McAtamney \& Corlett (1993)

Esse posicionamento configura uma pontuação +2 .

g) Qualificar a posição das pernas:

A funcionária exerce a atividade sentada com os pés bem apoiados e o peso bem distribuído, $\log 0$ a pontuação é +1 .

Uma vez encontrados as pontuações referentes ao pescoço, tronco e pernas, pode-se qualificar a postura de acordo com o Quadro 3.

Quadro 3 - Pontuação do pescoço, tronco e pernas

\begin{tabular}{|c|c|c|c|c|c|c|c|c|c|c|c|c|}
\hline \multirow{4}{*}{$\begin{array}{c}\text { Pontuação da } \\
\text { postura do } \\
\text { pescoço }\end{array}$} & \multicolumn{12}{|c|}{ Pontuaçāo da Postura do Tronco } \\
\hline & \multirow{2}{*}{\multicolumn{2}{|c|}{$\frac{1}{\text { Pernas }}$}} & \multicolumn{2}{|c|}{2} & \multicolumn{2}{|c|}{$\overline{3}$} & \multicolumn{2}{|c|}{$\overline{4}$} & \multicolumn{2}{|c|}{5} & \multicolumn{2}{|c|}{6} \\
\hline & & & & & & & & & & & & \\
\hline & 1 & 2 & 1 & 2 & 1 & 2 & 1 & 2 & 1 & 2 & 1 & 2 \\
\hline 1 & 1 & 3 & 2 & 3 & 3 & 4 & 5 & 5 & 6 & 6 & 7 & 7 \\
\hline 2 & 2 & 3 & 2 & 3 & 4 & 5 & 5 & 5 & 6 & 7 & 7 & 7 \\
\hline 3 & 3 & 3 & 3 & 4 & 4 & 5 & 5 & 6 & 6 & 7 & 7 & 7 \\
\hline 4 & 5 & 5 & 5 & 6 & 6 & 7 & 7 & 7 & 7 & 7 & 8 & 8 \\
\hline 5 & 7 & 7 & 7 & 7 & 7 & 8 & 8 & 8 & 8 & 8 & 8 & 8 \\
\hline 6 & 8 & 8 & 8 & 8 & 8 & 8 & 8 & 9 & 9 & 9 & $\overline{9}$ & $\overline{9}$ \\
\hline
\end{tabular}

Fonte: Adaptado de McAtamney \& Corlett (1993)

A pontuação da postura encontrada para atividade I no Quadro 3 foi de 5 pontos.

Depois da soma dos pontos obtidos, pode-se agora encontrar o resultado no Quadro 4, cruzando-se os dados dos Quadros 2 e 3 para se obter a pontuação final. 
Quadro 4 - Pontuação final

\begin{tabular}{|c|c|c|c|c|c|c|c|c|}
\hline \multirow{10}{*}{$\begin{array}{l}\text { PONTUAÇÃO } \\
\text { DE BRAÇO, } \\
\text { ANTEBRAÇO } \\
\text { E PUNHO }\end{array}$} & \multicolumn{8}{|c|}{ PONTUACุÃO DE PESCOÇO, TRONCO E PERNAS } \\
\hline & & 1 & 2 & 3 & 4 & 5 & 6 & $7+$ \\
\hline & 1 & 1 & 2 & 3 & 3 & 4 & 5 & 5 \\
\hline & 2 & 2 & 2 & 3 & 4 & 4 & 5 & 5 \\
\hline & 3 & 3 & 3 & 3 & 4 & 4 & 5 & 6 \\
\hline & 4 & 3 & 3 & 3 & 4 & 5 & 6 & 6 \\
\hline & 5 & 4 & 4 & 4 & 5 & 6 & 7 & 7 \\
\hline & 6 & 4 & 4 & 5 & 6 & 6 & 7 & 7 \\
\hline & 7 & 5 & 5 & 6 & 6 & 7 & 7 & 7 \\
\hline & $8+$ & 5 & 5 & 6 & 7 & 7 & 7 & 7 \\
\hline
\end{tabular}

Fonte: Adaptado de McAtamney \& Corlett (1993)

A pontuação da postura encontrada para atividade I no Quadro 4, foi de 4 pontos.

Para se chegar aos valores obtidos pelas atividades II, III e IV, seguiu-se a mesma metodologia utiliza para a atividade I. Os resultados encontram-se no Quadro 5.

Quadro 5 - Pontuação das atividades

\begin{tabular}{|c|c|c|c|}
\hline Atividade & Quadro 2 & Quadro 3 & Quadro 4 \\
\hline II & 1 & 2 & $\mathbf{2}$ \\
\hline III & 2 & 2 & $\mathbf{2}$ \\
\hline IV & 4 & 5 & $\mathbf{5}$ \\
\hline
\end{tabular}

Fonte: Autores (2020)

De acordo com os valores apresentados podemos enquadrar as atividades em diferentes níveis de ação, conforme o Quadro 6.

Quadro 6 - Níveis de ação

\begin{tabular}{|c|c|c|}
\hline NÍVEIS DE AÇÃO & & \\
\hline NÍVEL 1 & Pontuação de 1 - 2 & $\begin{array}{l}\text { Postura aceitável se não for repetida ou mantida durante longos } \\
\text { períodos }\end{array}$ \\
\hline NÍVEL 2 & Pontuação de 3 - 4 & $\begin{array}{c}\text { Investigar; possibilidade de requerer mudanças; é conveniente } \\
\text { introduzir alterações }\end{array}$ \\
\hline NÍVEL 3 & Pontuação de 5 - 6 & Investigar; realizar mudanças rapidamente \\
\hline NÍVEL 4 & Pontuação de $7+$ & Mudanças imediatas \\
\hline
\end{tabular}

Fonte: Adaptado de McAtamney \& Corlett (1993)

Dessa forma, os resultados obtidos de acordo com o RULA são os seguintes:

Atividade I: nível 2, atividade II: nível 1, atividade III: nível 1 e atividade IV: nível 3.

\subsection{Aplicação do questionário bipolar}

Com o intuito de avaliar a fadiga da operadora de checkout do restaurante durante o seu horário de trabalho, foi aplicado o Questionário Bipolar. As respostas obtidas podem ser verificadas nos Quadros 7, 8 e 9. 
Quadro 7 - Questionário Bipolar do início da jornada de trabalho (09h20min)

\begin{tabular}{|c|c|c|c|c|c|c|c|c|}
\hline & 1 & 2 & 3 & 4 & 5 & 6 & 7 & \\
\hline Descansado & & $\mathrm{X}$ & & & & & & Cansado \\
\hline Boa concentração & & & $\mathrm{X}$ & & & & & Dificuldade de concentrar \\
\hline Calmo & & $\mathrm{X}$ & & & & & & Nervoso \\
\hline Produtividade normal & & & $\mathrm{X}$ & & & & & Produtividade comprometida \\
\hline Descansado visualmente & & $\mathrm{X}$ & & & & & & Cansaço visual \\
\hline $\begin{array}{l}\text { Ausência de dor nos } \\
\text { músculos do pescoço e } \\
\text { ombros }\end{array}$ & & & $\mathrm{X}$ & & & & & $\begin{array}{l}\text { Dor nos músculos do pescoço e } \\
\text { ombros }\end{array}$ \\
\hline Ausência de dor nas costas & & & $\mathrm{X}$ & & & & & Dor nas costas \\
\hline $\begin{array}{c}\text { Ausência de dor na região } \\
\text { lombar }\end{array}$ & & & $\mathrm{X}$ & & & & & Dor na região lombar \\
\hline Ausência de dor nas coxas & $\mathrm{X}$ & & & & & & & Dor nas coxas \\
\hline Ausência de dor nas pernas & $\mathrm{x}$ & & & & & & & Dor nas pernas \\
\hline Ausência de dor nos pés & $\mathrm{X}$ & & & & & & & Dor nos pés \\
\hline Ausência de dor de cabeça & $\mathrm{x}$ & & & & & & & Dor de cabeça \\
\hline $\begin{array}{c}\text { Ausência de dor no braço, no } \\
\text { punho ou na mão do lado } \\
\text { direito }\end{array}$ & & $\mathrm{X}$ & & & & & & $\begin{array}{c}\text { Dor nos braço, no punho ou na } \\
\text { mão do lado direito }\end{array}$ \\
\hline $\begin{array}{c}\text { Ausência de dor no braço, no } \\
\text { punho ou na mão do lado } \\
\text { esquerdo }\end{array}$ & & $\mathrm{X}$ & & & & & & $\begin{array}{l}\text { Dor no braço, no punho ou na } \\
\text { mão do lado esquerdo }\end{array}$ \\
\hline
\end{tabular}

Fonte: Adaptado de Ergo LTDA (2020)

Quadro 8 - Questionário Bipolar do meio da jornada de trabalho (12:00h)

\begin{tabular}{|c|c|c|c|c|c|c|c|c|}
\hline & 1 & 2 & 3 & 4 & 5 & 6 & 7 & \\
\hline Descansado & & & & $\mathrm{X}$ & & & & Cansado \\
\hline Boa concentração & & & & $\mathrm{X}$ & & & & Dificuldade de concentrar \\
\hline Calmo & & & $\mathrm{X}$ & & & & & Nervoso \\
\hline Produtividade normal & & & $\mathrm{X}$ & & & & & Produtividade comprometida \\
\hline Descansado visualmente & & & & $\mathrm{X}$ & & & & Cansaço visual \\
\hline $\begin{array}{l}\text { Ausência de dor nos } \\
\text { músculos do pescoço e } \\
\text { ombros }\end{array}$ & & & $\mathrm{X}$ & & & & & $\begin{array}{l}\text { Dor nos músculos do pescoço e } \\
\text { ombros }\end{array}$ \\
\hline Ausência de dor nas costas & & & & & $\mathrm{X}$ & & & Dor nas costas \\
\hline $\begin{array}{c}\text { Ausência de dor na região } \\
\text { lombar }\end{array}$ & & & & & $\mathrm{X}$ & & & Dor na região lombar \\
\hline Ausência de dor nas coxas & & $\mathrm{X}$ & & & & & & Dor nas coxas \\
\hline Ausência de dor nas pernas & & $\mathrm{X}$ & & & & & & Dor nas pernas \\
\hline Ausência de dor nos pés & & $\mathrm{X}$ & & & & & & Dor nos pés \\
\hline Ausência de dor de cabeça & & $\mathrm{X}$ & & & & & & Dor de cabeça \\
\hline $\begin{array}{c}\text { Ausência de dor no braço, } \\
\text { no punho ou na mão do } \\
\text { lado direito }\end{array}$ & & & $\mathrm{x}$ & & & & & $\begin{array}{c}\text { Dor no braço, no punho ou na } \\
\text { mão do lado direito }\end{array}$ \\
\hline $\begin{array}{c}\text { Ausência de dor no braço, } \\
\text { no punho ou na mão do } \\
\text { lado esquerdo }\end{array}$ & & & $\mathrm{x}$ & & & & & $\begin{array}{l}\text { Dor no braço, no punho ou na } \\
\text { mão do lado esquerdo }\end{array}$ \\
\hline
\end{tabular}

Fonte: Adaptado de Ergo LTDA (2020) 
Quadro 9 - Questionário Bipolar do final da jornada de trabalho (15:00h)

\begin{tabular}{|c|c|c|c|c|c|c|c|c|}
\hline & 1 & 2 & 3 & 4 & 5 & 6 & 7 & \\
\hline Descansado & & & & & $\mathrm{X}$ & & & Cansado \\
\hline Boa concentração & & & $\mathrm{X}$ & & & & & Dificuldade de concentrar \\
\hline Calmo & & & $\mathrm{X}$ & & & & & Nervoso \\
\hline Produtividade normal & & & & $\mathrm{X}$ & & & & Produtividade comprometida \\
\hline Descansado visualmente & & & & & $\mathrm{X}$ & & & Cansaço visual \\
\hline $\begin{array}{l}\text { Ausência de dor nos } \\
\text { músculos do pescoço e } \\
\text { ombros }\end{array}$ & & & & $\mathrm{X}$ & & & & $\begin{array}{l}\text { Dor nos músculos do pescoço e } \\
\text { ombros }\end{array}$ \\
\hline Ausencia de dor nas costas & & & & & & & $\mathrm{X}$ & Dor nas costas \\
\hline $\begin{array}{c}\text { Ausência de dor na região } \\
\text { lombar }\end{array}$ & & & & & & & $\mathrm{X}$ & Dor na região lombar \\
\hline Ausência de dor nas coxas & & & $\mathrm{X}$ & & & & & Dor nas coxas \\
\hline Ausência de dor nas pernas & & & $\mathrm{X}$ & & & & & Dor nas pernas \\
\hline Ausência de dor nos pés & & $\mathrm{x}$ & & & & & & Dor nos pés \\
\hline Ausência de dor de cabeça & & & $\mathrm{X}$ & & & & & Dor de cabeça \\
\hline $\begin{array}{c}\text { Ausência de dor no braço, } \\
\text { no punho ou na mão do } \\
\text { lado direito }\end{array}$ & & & & $\mathrm{X}$ & & & & $\begin{array}{c}\text { Dor no braço, no punho ou na } \\
\text { mão do lado direito }\end{array}$ \\
\hline $\begin{array}{c}\text { Ausência de dor no braço, } \\
\text { no punho ou na mão do } \\
\text { lado esquerdo }\end{array}$ & & & & $\mathrm{X}$ & & & & $\begin{array}{l}\text { Dor no braço, no punho ou na } \\
\text { mão do lado esquerdo }\end{array}$ \\
\hline
\end{tabular}

Fonte: Adaptado de Ergo LTDA (2020)

De acordo com os resultados obtidos com os questionários, podemos classificar o nível de fadiga de acordo com os critérios expostos no Quadro 10.

Quadro 10 - Nível de fadiga do funcionário

\begin{tabular}{|c|l|}
\hline TIPO DE FADIGA & \multicolumn{1}{c|}{ DESCRIÇÃO } \\
\hline \multicolumn{2}{|c|}{ CONSIDERANDO O QUESTIONARIO DO INÍCIO DA JORNADA } \\
\hline FADIGA ACUMULADA & $\begin{array}{l}\text { Pontuação 4 ou superior para os itens: dor nos músculos } \\
\text { do pescoço e ombros e dor nos braços (considerando } \\
\text { também que as queixas nos aspectos citados continuem ao } \\
\text { longo da jornada de trabalho); }\end{array}$ \\
\hline AUSÊNCIA DE FADIGA & Pontuação até 3 em cada um dos itens; \\
\hline MODERADA & $\begin{array}{l}\text { Pontuação 4 ou 5 em alguns itens (considerando que } \\
\text { anteriormente possuíam pontuação menor que 3); }\end{array}$ \\
\hline INTENSA & Pontuação 6 ou 7 em alguns itens; \\
\hline
\end{tabular}

Fonte: Adaptado de Ergo LTDA (2020)

\subsection{Avaliação de satisfação dos trabalhadores}

Para realização do diagnóstico acerca da satisfação da colaboradora em relação às atividades exercidas, foi elaborado um questionário semiestruturado, analisando diversos aspectos em uma escala de 1 a 5, onde: 1 (Péssimo), 2 (Ruim), 3 (Moderado), 4 (Bom) e 5 (Excelente). Os resultados obtidos estão apresentados na Figura 8. 
Figura 8 - Avaliação do trabalho

\section{Avaliação dos aspectos definidos}

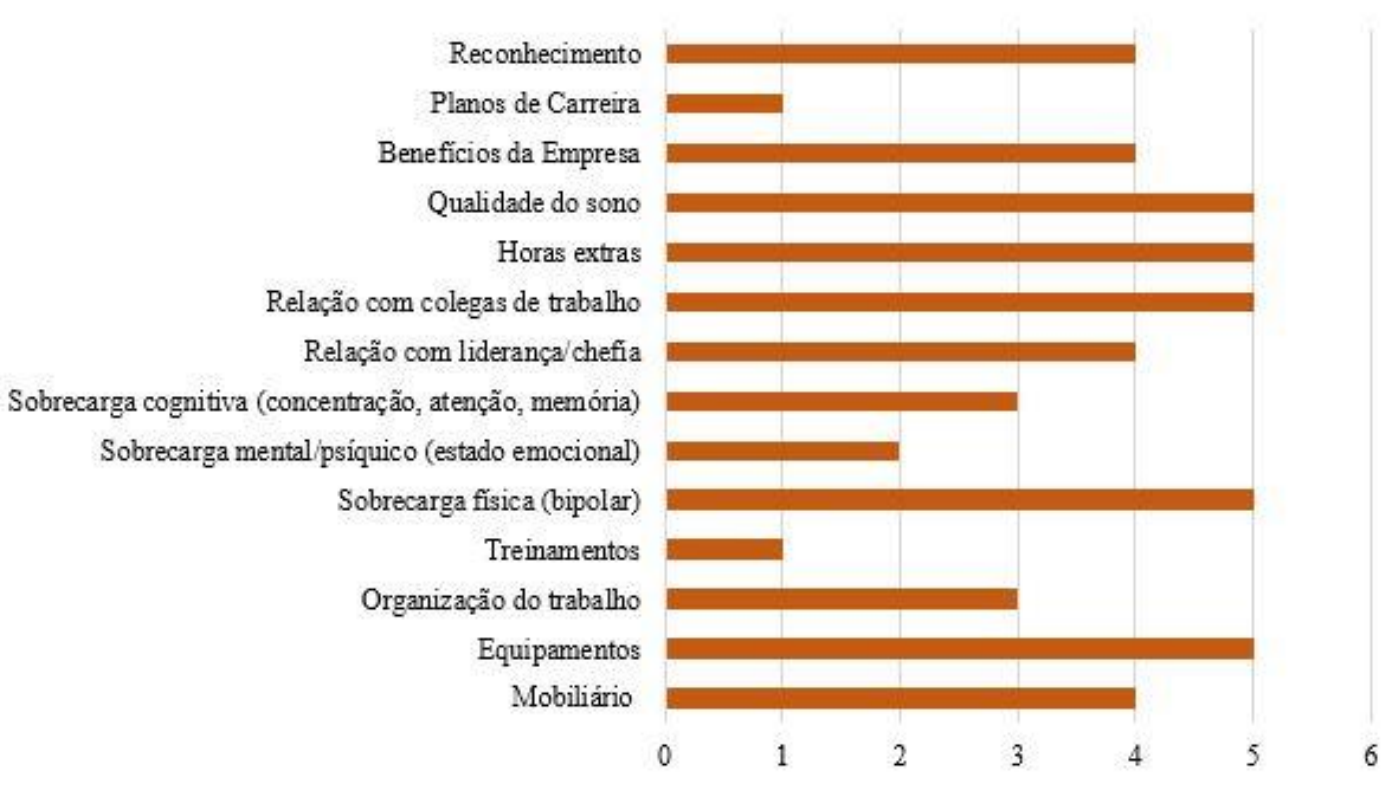

Fonte: Autores (2020)

Algumas observações realizadas pela colaboradora foram: há dificuldades no treinamento remoto, sobrecarga mental devido ao estresse advindo de relações com clientes, sobrecarga cognitiva pois operações que envolvem dinheiro requerem maior atenção e não há plano de carreira.

\subsection{Roteiro de problematizações e diagnósticos}

Através da aplicação do RULA, verificou-se que a atividade I, enquadrada no nível 2, precisa ser investigada, pois há possibilidades de requerer mudanças. As atividades II e III estão enquadradas no nível 1, o qual corresponde a uma postura aceitável, contanto que não seja mantida por um longo período, assim, não há necessidade de medidas imediatas. Já a atividade IV, enquadra-se no nível 3, que impõe a realização de mudanças rapidamente. A obtenção desses resultados pode se dar ao fato da colaboradora ter que usar, na maior parte das atividades, o alcance máximo dos seus braços. De uma forma geral, os resultados indicaram que há problemas em relação à postura adotada pela funcionária.

Tal fato se confirma através dos resultados obtidos com a aplicação do questionário bipolar. De acordo com as respostas ofertadas pela colaborada, ao final da sua jornada de trabalho, ela relata sentir um cansaço físico e visual (nível 5). Este fato pode comprometer a sua produtividade, a qual ela aponta como nível 4, sendo que no início da atividade o comprometimento era de nível 3. 
Outros itens apontados como nível 4 correspondem a dores no pescoço e nos ombros, bem como nos braços e nos punhos, indicando um quadro de fadiga moderada. O resultado mais preocupante diz respeito à análise de dores nas costas e na lombar, as quais atingiram o nível 7 (maior índice na escala de pontuação), demostrando uma fadiga intensa.

Uma análise dos fatores que compõem o ambiente de trabalho pode ajudar a entender os resultados obtidos. A cadeira não é regulável, indo de encontro à NR-17 (2018, p.4), a qual afirma no item 2.1 do Anexo I que, para operadores de checkout deve-se "manter uma cadeira de trabalho com assento e encosto para apoio lombar, com estofamento de densidade adequada, ajustáveis à estatura do trabalhador e à natureza da tarefa”. A cadeira utilizada não permite flexibilidade em relação à altura e nem variações de postura que podem ajudar a aliviar as tensões musculares.

Outro requisito imposto pela norma que não é cumprido é "colocar apoio para os pés, independente da cadeira" (NR-17, 2018, p.4). Quanto ao espaço de trabalho para realização das atividades, o ambiente é considerado adequado. Em relação às condições ambientais, não se dispôs de equipamentos para uma análise quantitativa, no entanto, uma entrevista não estruturada foi realizada com a funcionária, que relatou não sentir nenhum desconforto quanto a estas.

A colaboradora afirmou, na avaliação do trabalho, que possui um bom relacionamento com a chefia e com os colegas de ofício. No entanto, há problemas com clientes, característico de tarefas que possuem um alto grau de relacionamento interpessoal, o que pode levar ao aumento de estresse. Ainda em relação a esta avaliação, deve-se dar destaque às piores pontuações, que correspondem ao treinamento e planos de carreira. $\mathrm{O}$ treinamento inadequado compromete a eficiência do serviço e gera problemas com os clientes, aumentado o nível de estresse advindo dessa relação. Já a ausência de um plano de carreira pode vir a desestimular a funcionária, pois causa nesta a falta de perspectiva de crescimento dentro da empresa.

\subsection{Recomendações}

Diante do que foi exposto, a empresa deve adotar algumas medidas para modificar seu sistema de trabalho, visando adequá-lo à realidade do trabalhador. A primeira sugestão visa corrigir os problemas encontrados em relação às dores apresentadas pela colaboradora (principalmente nas costas e na lombar) e diz respeito à aquisição de uma cadeira de escritório regulável (Figura 9). 
Figura 9 - Cadeira regulável

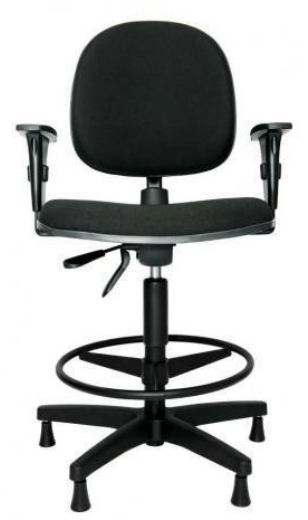

Fonte: Google Imagens (2020)

Também é recomendada a aquisição de um apoio para os pés, conforme orienta a NR-17 (Figura 10).

Figura 10 - Apoiador para pés

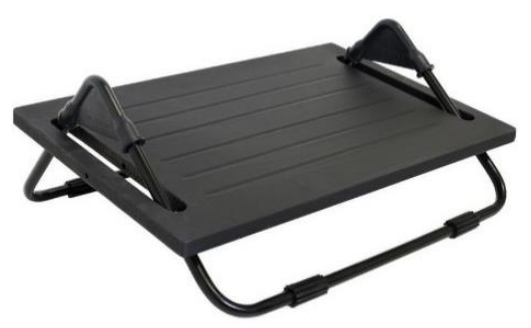

Fonte: Google Imagens (2020)

Percebe-se ainda, através da Figura 11, que para alcançar a impressora, a funcionária utiliza o alcance máximo do braço, que é de $63 \mathrm{~cm}$, o que exige um maior esforço.

Figura 11 - Alcance máximo e ótimo

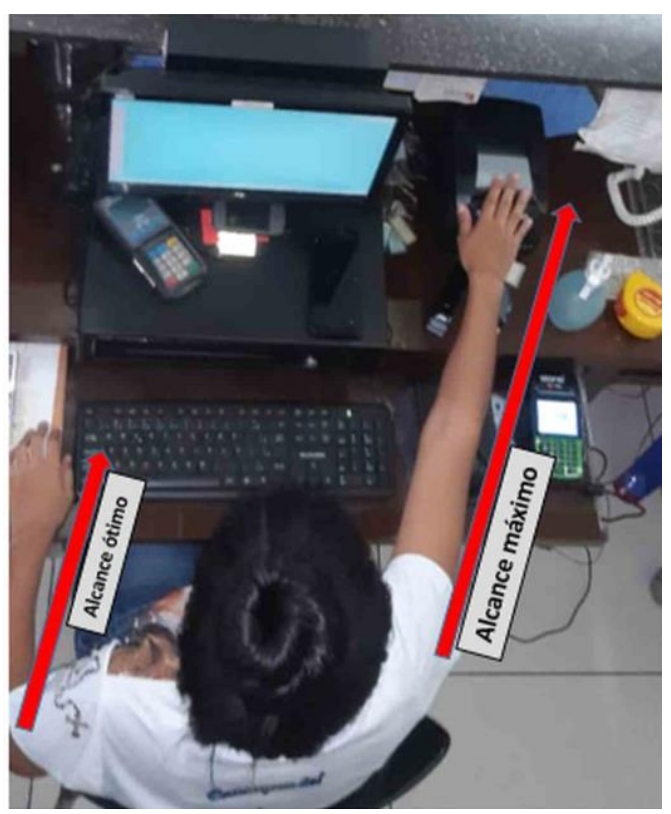

Fonte: Autores (2020) 
Dessa forma, a impressora pode ser trazida para o plano inferior da mesa, ficando mais próxima à funcionária e permitindo que esta utilize o seu alcance ótimo, que é de $47 \mathrm{~cm}$.

Em relação à ergonomia cognitiva, é importante buscar melhorias em relação ao treinamento, para que a funcionária se sinta mais confiante e para que se evitem possíveis problemas com a clientela. Outro ponto a ser considerado é a implementação de um plano de carreira de forma que a colaboradora possa se sentir valorizada e motivada a exercer da melhor forma o seu trabalho, visando ganhos futuros.

\subsection{Plano de ação}

Para auxiliar na atuação das recomendações descritas no tópico anterior, a ferramenta $5 \mathrm{~W} 2 \mathrm{H}$ foi utilizada no planejamento das ações necessárias para o alcance dos objetivos. Os planos propostos são apresentados nos Quadros 11, 12, 13 e 14.

Quadro 11 - 5W2H para a cadeira regulável

\begin{tabular}{|c|c|}
\hline \multicolumn{2}{|r|}{$5 \mathrm{~W} 2 \mathrm{H}$ - Cadeira regulável } \\
\hline $\begin{array}{l}\text { O que será feito? } \\
\text { (What) }\end{array}$ & Compra de uma cadeira de escritório regulável \\
\hline $\begin{array}{l}\text { Quando será feito? } \\
\text { (When) }\end{array}$ & Imediatamente \\
\hline $\begin{array}{l}\text { Onde será feito? } \\
\text { (Where) }\end{array}$ & No setor de checkout \\
\hline $\begin{array}{l}\text { Porque será feito? } \\
\text { (Why) }\end{array}$ & $\begin{array}{c}\text { Para melhorar o conforto do trabalhador, bem como evitar } \\
\text { prejuizos à sua saúde }\end{array}$ \\
\hline $\begin{array}{l}\text { Quem fará? } \\
\text { (Who) }\end{array}$ & Gerente do setor de compra \\
\hline $\begin{array}{l}\text { Como será feito? } \\
\text { (How) }\end{array}$ & $\begin{array}{c}\text { Realizando uma pesquisa em diversas lojas fisicas e virtuais } \\
\text { para analisar o melhor custo-beneficio }\end{array}$ \\
\hline $\begin{array}{l}\text { Quanto custará? } \\
\text { (How much) }\end{array}$ & Entre 300,00 e $600,00 \mathrm{R} \$$ \\
\hline
\end{tabular}

Fonte: Autores (2020)

Quadro 12 - 5W2H para o apoiador para os pés

\begin{tabular}{|c|c|}
\hline $\begin{array}{c}\text { O que será feito? } \\
\text { (What) }\end{array}$ & Compra de um apoiador para os pés \\
\hline $\begin{array}{c}\text { Quando será feito? } \\
\text { (When) }\end{array}$ & Imediatamente \\
\hline $\begin{array}{c}\text { Onde será feito? } \\
\text { (Where) }\end{array}$ & No setor de checkout \\
\hline $\begin{array}{c}\text { Porque será feito? } \\
\text { (Why) }\end{array}$ & $\begin{array}{c}\text { Para melhorar o conforto do trabalhador, bem como evitar } \\
\text { prejuizos à sua saúde }\end{array}$ \\
\hline $\begin{array}{c}\text { Quem fará? } \\
\text { (Who) }\end{array}$ & Gerente do setor de compra \\
\hline $\begin{array}{c}\text { Como será feito? } \\
\text { (How) }\end{array}$ & $\begin{array}{c}\text { Realizando uma pesquisa em diversas lojas fisicas e virtuais } \\
\text { para analisar o melhor custo-beneficio }\end{array}$ \\
\hline $\begin{array}{c}\text { Quanto custará? } \\
\text { (How much) }\end{array}$ & Entre 40,00 e 70,00 R\$ \\
\hline
\end{tabular}

Fonte: Autores (2020) 
Quadro 13 - 5W2H para o trienamento

\begin{tabular}{|c|c|}
\hline $\begin{array}{c}\text { O que será feito? } \\
\text { (What) }\end{array}$ & $\begin{array}{c}\text { Adotar novas metodologias em relação ao treinamento para } \\
\text { o sistema utilizado }\end{array}$ \\
\hline $\begin{array}{c}\text { Quando será feito? } \\
\text { (When) }\end{array}$ & As datas devem ser acordadas com a empresa terceirizada \\
\hline $\begin{array}{c}\text { Onde será feito? } \\
\text { (Where) }\end{array}$ & No setor de checkout \\
\hline $\begin{array}{c}\text { Porque será feito? } \\
\text { (Why) }\end{array}$ & $\begin{array}{c}\text { Para melhorar a confiança do trabalhador em relação à } \\
\text { execuço do seu trabalho e evitar possiveis problemas com } \\
\text { os clientes }\end{array}$ \\
\hline $\begin{array}{c}\text { Quem fará? } \\
\text { (Who) }\end{array}$ & Empresa terceirizada responsável pelo sistema \\
\hline $\begin{array}{c}\text { Como será feito? } \\
\text { (How) }\end{array}$ & $\begin{array}{c}\text { Realização de vídeo-conferências para melhorar a forma de } \\
\text { interação e aprendizado }\end{array}$ \\
\hline $\begin{array}{c}\text { Quanto custará? } \\
\text { (How much) }\end{array}$ & $\begin{array}{c}\text { A empresa não terá custo extra em relação ao treinamento; a } \\
\text { adoção de novas metodologias deve ser negociada com o } \\
\text { terceirizado }\end{array}$ \\
\hline \multicolumn{2}{|c|}{} \\
\hline
\end{tabular}

Fonte: Autores (2020)

Quadro 14 - 5W2H para o plano de carreira

\begin{tabular}{|c|c|}
\hline \multicolumn{2}{|r|}{$5 \mathrm{~W} 2 \mathrm{H}$ - Plano de carreira } \\
\hline $\begin{array}{l}\text { O que será feito? } \\
\text { (What) }\end{array}$ & $\begin{array}{c}\text { Implementação de um plano de carreira para a } \\
\text { funcionária }\end{array}$ \\
\hline $\begin{array}{l}\text { Quando será feito? } \\
\text { (When) }\end{array}$ & Até o final do ano de 2020 \\
\hline $\begin{array}{l}\text { Onde será feito? } \\
\text { (Where) }\end{array}$ & No setor de checkout \\
\hline $\begin{array}{l}\text { Porque será feito? } \\
\text { (Why) }\end{array}$ & Para motivar a funcionária \\
\hline $\begin{array}{l}\text { Quem fará? } \\
\text { (Who) }\end{array}$ & A alta gerência \\
\hline $\begin{array}{l}\text { Como será feito? } \\
\text { (How) }\end{array}$ & $\begin{array}{l}\text { Através de uma reunião entre a alta gerência e os setores } \\
\text { financeiro e de } \mathrm{RH}\end{array}$ \\
\hline $\begin{array}{l}\text { Quanto custará? } \\
\text { (How much) }\end{array}$ & Irá depender do plano estabelecido pela alta gerência \\
\hline
\end{tabular}

Fonte: Autores (2020)

A principal característica aqui seguida foi a clareza, de modo a facilitar a implantação e efetividade do plano de ação, garantindo assim a validade do estudo.

\section{Considerações finais}

O presente estudo consistiu em avaliar as condições ergonômicas as quais está submetida a operadora de caixa de um restaurante, localizado no município de Mossoró-RN. Para isso utilizou-se de ferramentas ergonômicas como o RULA e o Questionário Bipolar, além de questionários e entrevistas semiestruturadas. 
Como resultados das investigações, obteve-se a existência de problemas na postura de trabalho da colaboradora, devido principalmente a utilização do seu alcance máximo para a realização da maioria das atividades. Evidenciou-se também que ao final da jornada de trabalho a funcionária possuía índices moderados de cansaço visual e dores no pescoço, ombros, braços e punhos, além de uma fadiga intensa com relação às dores sentidas nas costas e lombar, todas advindos principalmente dos fatores que compõem o seu ambiente de trabalho que não estavam de acordo com a NR-17, exigindo, portanto, mudanças.

Mediante os problemas apresentados, elaborou-se algumas recomendações para proporcionar melhor qualidade de trabalho à funcionária em questão. Para isto, desenvolveu-se um plano de ação para cada sugestão estabelecida por intermédio da ferramenta $5 \mathrm{~W} 2 \mathrm{H}$, a fim de viabilizar a implantação das melhorias de forma adequada.

À vista do exposto, denota-se a relevância envolvida na realização de estudos ergonômicos nos diversos postos de trabalho das organizações, uma vez que, a partir do momento em que as condições de trabalho encontram-se adequadas aos colaboradores, estes conseguem realizar as atividades de forma apropriada, proporcionando às empresas o alcance dos seus objetivos. Para trabalhos futuros sugere-se a implantação das mudanças propostas a fim de tornar possível a verificação e validação das melhorias nas condições de trabalho aqui apresentadas, bem como uma análise ambiental, não realizada devido à falta de instrumentos necessários.

\section{REFERÊNCIAS}

ABRAHÃO, J. Introdução à ergonomia: da prática à teoria. São Paulo: Blucher, 2009.

BRAGA, Juliana Celeste Matos; ZILLE, Luciano Pereira; BRAGA, Luana Matos; ZILLE, Diego Pereira. Tensões no trabalho: estudo com operadores de caixa de uma rede mineira de supermercados. Revista Eletrônica da Administração (Online). Centro Universitário de Franca Uni-FACEF. Franca - SP, v.12, n.1, ed.22, p.15-30, jan-jun, 2013.

BRASIL. Ministério do Trabalho e Emprego. NR 17 - Ergonomia. Portaria MTb n. ${ }^{\circ} 876$, de 24 de outubro de 2018.

DAYCHOUM, Merhi. 40 Ferramentas e técnicas de gerenciamento. 1. ed. Rio de Janeiro: Brasport, 2012.

ERGO LTDA. Questionário bipolar de fadiga. Disponível em:

<http://www.ergoltda.com.br/downloads/questionario_bipolar_ava_fadiga.pdf>. Acesso em: 13 mai. 2020.

FACHIN, Odília. Fundamentos de metodologia: noções básicas em pesquisa científica. 6. ed. São Paulo: Saraiva, 2017. 
DOPPLER, F. Trabalho e saúde. In: FALZON, P. Ergonomia. 2.ed. São Paulo: Blucher, 2018.

GUÉRIN, F; LAVILLE, A; DANIELLOU, F; DURAFFOURG, J; KERGUELEN, A. Compreender o trabalho para transformá-lo: a prática da ergonomia. 1. ed. São Paulo: Blucher, 2001.

IIDA, Itiro. Ergonomia: projeto e produção. 2 ed. São Paulo: Edgard Blucher, 2005.

IIDA, Itiro; BUARQUE, Lia. Ergonomia: projeto e produção. 3 ed. São Paulo: Edgard Blucher, 2016.

MACHADO, S. S. Gestão da qualidade. Santa Maria: Universidade Federal de Santa Maria, 2012.

MCATAMNEY, Lynn; CORLETT, E Nigel. RULA: A survey method for the investigation of work-related upperlimb disorders. Applied Ergonomics, v.24, n.2, p.91-99, April, 1993.

SILVA, Pedro Henrique Souza da; CABETE, Nadja Polyana Felizola. Aplicação do Questionário Bipolar na avaliação da fadiga e da dor em uma unidade técnica de uma autarquia federal na cidade de Manaus. Simpósio de Engenharia de Produção. Universidade Federal de Goiás - Regional Catalão, 28 a 30 de agosto, Catalão, Goiás, Brasil. 